The Encyclopedia of Biological Invasions is a comprehensive and authoritative reference dealing with all the physical and biological aspects of invasive species and invasion biology and theory. The articles are written by researchers and scientific experts and provide a broad overview of the current state of knowledge with respect to the patterns and processes of invasion, the theories associated with invasion, and particular accounts of organisms that have become invasive. Biologists, ecologists, environmental scientists, geographers, botanists, and zoologists have contributed reviews intended for students as well as for the interested general public.

To aid the reader in using this reference, the following summary describes this Encyclopedia's features, reviews its organization and the format of the articles, and is a guide to the many ways to maximize the utility of this Encyclopedia.

\section{SUBJECT AREAS}

The Encyclopedia of Biological Invasions includes 153 topics that review the various ways scholars have studied invasive species. The Encyclopedia comprises the following subject areas:

- Invader Attributes

- Ecosystem Features

- Processes

- Impacts

- Notable Taxa

- Pathways to Invasion

- Management and Regulation

- History

- Notable Invasions

\section{ORGANIZATION}

Articles are arranged alphabetically by title. An alphabetical table of contents begins on page $\mathrm{v}$, and another table of contents with articles arranged by subject area begins on page ix.
Article titles have been selected to make it easy to locate information about a particular topic. Each title begins with a key word or phrase, sometimes followed by a descriptive term. For example, "Genotypes, Invasive" is the title assigned rather than "Invasive Genotypes," because genotypes is the key term and is thus more likely to be sought by readers. Articles that might reasonably appear in different places in the Encyclopedia are listed under alternative titles-one title appears as the full entry; the alternative title directs the reader to the full entry. For example, the alternative title "Coccinellidae" refers readers to the entry entitled "Ladybugs."

\section{ARTICLE FORMAT}

Because the articles in the Encyclopedia are intended for the interested general public, each article begins with an introduction that gives the reader a short definition of the topic and its significance. Here is an example of an introduction from the article "Phytophthora":

Phytophthora is a genus of approximately Ioo species of fungal-like, plant pathogenic organisms classified in the kingdom Stramenopila. Often known as "water molds," Phytophthora species have a swimming spore stage (when they are known as zoospores). Phytophthora species are well known as pathogens of agricultural, ornamental, and forest plants. Across the genus, individual Phytophthora species may infect roots, stems, leaves, flowers, or fruits of susceptible plants and cause dieback, decline, or death. Some Phytophthora species are specialists (infecting only one or a few plant species), and others are generalists (infecting many plant species across several or many plant families). The diversity of Phytophthora is quite astounding, and many new species have been described in the past ten years. In addition, Phytophthora species have become one of most important causes of emerging diseases in native plant communities. 
Within most articles, and especially the longer articles, major headings help the reader identify important subtopics within each article. The article "Melastomes" includes the following headings: "Naturalized and Invasive Melastomes," "Diversity of Life Forms and Habitats," "Reasons for Success," "Impacts and Control Methods," and "Conclusions."

\section{CROSS-REFERENCES}

Many of the articles in this Encyclopedia concern topics for which articles on related topics are also included. In order to alert readers to these articles of potential interest, crossreferences are provided at the conclusion of each article. At the end of "Disturbance," the following text directs readers to other articles that may be of special interest:

\section{SEE ALSO THE FOLLOWING ARTICLES}

Fire Regimes / Invasibility, of Communities and Ecosystems /

Land Use / Restoration / Succession / Transformers

Readers will find additional information relating to Disturbance in the articles listed.

\section{BIBLIOGRAPHY}

Every article ends with a short list of suggestions for "Further Reading." The sources offer reliable in-depth information and are recommended by the article's author or authors as the best available publications for more lengthy, detailed, or comprehensive coverage of a topic than can be feasibly presented within this Encyclopedia. The citations do not represent all of the sources employed by the contributor in preparing the article. Most of the listed citations are to review articles, recent books, or specialized textbooks, except in rare cases of classic, ground-breaking scientific articles or articles dealing with subject matter that is especially new and newsworthy. Thus, the reader interested in delving more deeply into any particular topic may elect to consult these secondary sources. This Encyclopedia functions as ingress into a body of research only summarized herein.

\section{GLOSSARY}

Almost every topic in the Encyclopedia deals with a subject that has specialized scientific vocabulary. An effort was made to avoid the use of scientific jargon, but introducing a topic can be very difficult without using some unfamiliar terminology. Therefore, each contributor was asked to define a selection of terms used commonly in discussion of their topic. All these terms have been collated into a glossary at the back of the volume after the last article. The glossary in this work includes over 600 terms.

\section{APPENDICES}

Owing to the great number of currently invasive organisms, it is not possible to include an account of every invasive species in this Encyclopedia. Therefore, the editors have included, as an appendix, the IUCN list of the world's worst Ioo invasive species. (Note that many other species have also been documented as invasive.) A second appendix lists key references-important book/volume references on biological invasions.

\section{INDEX}

The last section of the Encyclopedia of Biological Invasions is a subject index consisting of more than 3,800 entries. This index includes subjects dealt with in each article, scientific names, topics mentioned within individual articles, and subjects that might not have warranted a separate, stand-alone article.

\section{ENCYCLOPEDIA WEBSITE}

To access the Encyclopedia of Biological Invasions website, please visit

http://www.ucpress.edu/books.php?isbn=9780520264212

This site provides a list of the articles, the contributors, several sample articles, published reviews, and links to a secure website for ordering copies of the Encyclopedia. The content of this site will evolve with the addition of new information. 